\title{
The Origin and Resolution of Conflicts in Animal Societies
}

The Case of the Bees and the Birds

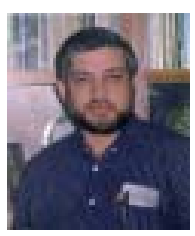

Raghavendra G adagkar, who studies and teaches animal behaviour at the Centre for Ecological Sciences, Indian Institute of Science and J awaharlal N ehru Centre for Advanced Scientific Research has a particular fascination for social insects such as ants, bees and wasps. He hopes to provide a D arwinian explanation for the altruism, courage, industry, sacrifice and such other seemingly human attributes of these insects.

\section{R aghavendra $\mathbf{G}$ adagkar}

Conflicts are ubiquitous in the living world. Especially in social animals, there are many subtle and complex conflicts whoseorigin and resol ution are hard to understand; success in doing so has only been achieved rather recently. Somewhat paradoxically, it required an understanding of the mechanism of evolution of altruism before one could attempt to understand the origin and resolution of these conflicts. I will first discuss our current understanding of the evolution of altruism and then discuss two examples of recent attempts to understand the origin and resolution of conflicts: (1) conflicts in somebirdson who should breed, father or son and (2) conflicts in hon ey bees on whether to beniceto their brothers or to their nephews.

Conflicts can be of many kinds. There is conflict between prey and their predators, between parasites and their hosts and even between members of the same species when they compete for limited resources. Since evolution by natural selection is based on competition and survival of the fittest, the existence of these kinds of conflicts is not surprising. This article is therefore not about these 'expected' conflicts. It is instead about other more subtleand rather unexpected conflicts. A remarkable fact in the history of the study of conflicts is that an understanding of the mechanism of evolution of altruism (the opposite of conflict) was necessary before we could even discover the existence of many kinds of subtle conflicts. T oday we have a well developed theory that not only explains the evolution of altruism but also predicts the existence of many subtle conflicts and provides ways of understanding how they might be resolved. 


\section{T he Paradox of Altruism ${ }^{1}$}

Consider the behaviour of the honey bees (F igure 1 ). A colony of honey bees may consist of tens of thousands of individuals but only one of them is the queen. All the other female bees are workers - who are much smaller than the queen and also have other morphological and anatomical adaptations that fit them for a life of working for the colony. D epending on the season, the colony may also consist of a small number of males, also called drones. Since the drones do no work for the colony and the queen is virtually an egg-laying machine, all the tasks of nest building, brood care, nest defense and foraging fall to the workers. A part from laying a few unfertilized eggs (which develop into drones) in the unlikely event of the queen's death, the workers have no reproductive options of their own. Thus they spend their whole lives working and caring for the queen and her brood - an act of supreme sacrifice or altruism (F igure 2).

If that's not sacrifice enough, consider this. The sting of the worker beeis armed with barbs pointing away from its tip so that when firmly lodged in the victim's skin, it cannot be withdrawn. When the bee attempts to fly away after stinging, the sting, the poison gland, and a part of its digestive system aretorn away and left attached to the victim. This ensures efficient delivery of the venom into the victim's body since the poison gland keeps pumping venom some 30 to 60 seconds after the bee has flown away. But for the bee, stinging is an act of suicide in an attempt to protect the colony.

The worker bee's altruism is not just remarkable from a human point of view; it is also paradoxical from the point of view of D arwin's theory of natural selection. H ow can natural selection, which is based on struggle for existence and survival of the fittest, promote the spread of such al truism? Will not al truists be eliminated by their selfish competitors, in the struggle for existence? D arwin referred to the worker bee as a 'special difficulty, which at first appeared to me insuperable, and actually fatal to my whole theory'. Clearly we need to modify the theory

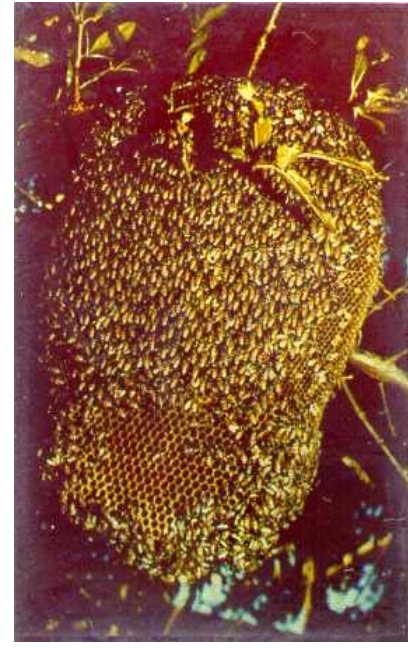

Figure 1. Apis florea, the Asian dwarf honey bee. These bees are the most primitive of all honey bees, but they exhibit levels of social organization and dance communication similar to those of other honey bee species. Further study of Apis florea may well reveal important information about the evolution of honey bees.

${ }^{1}$ Terms such as 'altruism', 'nepotism', 'selfishness', 'sacrifice' etc., are routinely used in studies of animal behaviour and evolutionary biology merely for the sake of convenience. However, they are objectively defined in terms of the consequences for the biological fitness of the actors and the recipients of the behavioural acts and they should by no means be construed as having any moral connotations that are inevitable when necessary to assume that animals are conscious of their actions in the same way that humans usually are. 
Figure 2. The consequences of interaction between animals. The recipient here is the actor's brother and therefore shares $\mathbf{5 0}$ percent of his genes, as is indicated by the shading. Help of any kind (the offering of food or shelter, easing access to a mate, and so on) is indicated by a vessel, and harmful behaviour by an axe. Selfishness: The selfish individual reduces his brother's fitness but increases his own to an extent that more than equals the brother's loss. Altruism: The altruist diminishes his own genetic fitness but raises his brother's fitness to the extent that the shared genes are actually increased in the next generation (Based on E O Wilson, 1975).

2 A locus is the position of a given gene on a chromosome. Alleles are different forms of a gene occupying a given locus.

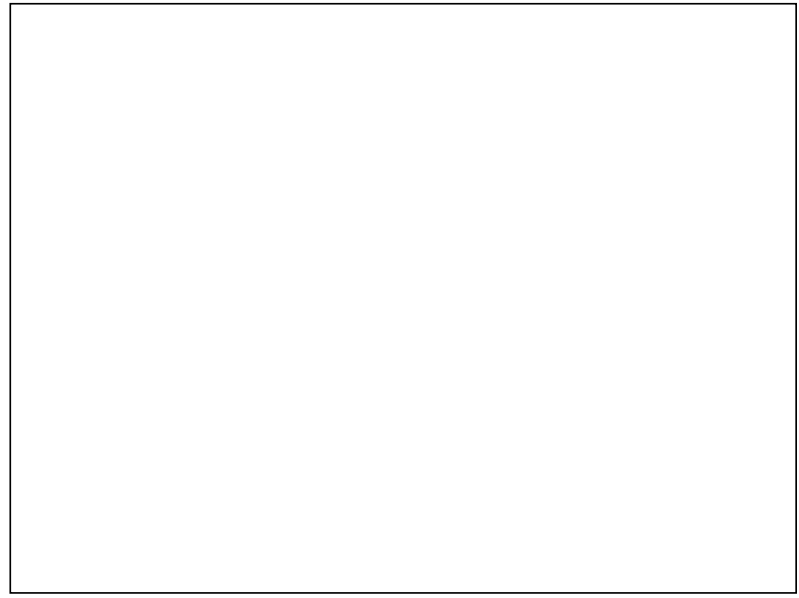

of natural selection to accommodate this difficulty. In an obscure little articlein a now defunct magazine called $\mathrm{P}$ enguin $\mathrm{N}$ ew B iology, J B S H aldane sowed the seeds of an idea that suggests how we might make the required modification. Although few people have read $\mathrm{H}$ aldane's article in the ori ginal, there is a very popular story, attributed to $\mathrm{H}$ aldane, that goes something like this: $\mathrm{H}$ aldane was once walking on the bank of a river with a friend. As was typical of him, $\mathrm{H}$ aldane paused for a moment, made a quick calculation on the palm of his hand, and declared: "If one or two of my brothers were drowning in this river, I might perhaps not risk my life to save them but if more than two of my brothers were drowning, I might attempt to save them at a risk to my life." (Figure 3).

\section{Inclusive Fitness}

W $\mathrm{D} \mathrm{H}$ amilton has given us a formal theory that can provide a satisfactory solution to $\mathrm{D}$ arwin'sinsuperabledifficulty. $\mathrm{H}$ amilton argued that al truism is no paradox at all if we realize that natural selection is dependent on changes in the relative frequencies of genes (alleles) ${ }^{2}$ regardless of the path way by which the change is brought about. What this means of course is that producing offspring is only one way to increase the representation of one's genes in the population. Aiding genetic relatives who carry copies of one's genes is another, equal ly legitimate, way of doing so. To put it more starkly you can be sterile and still have 


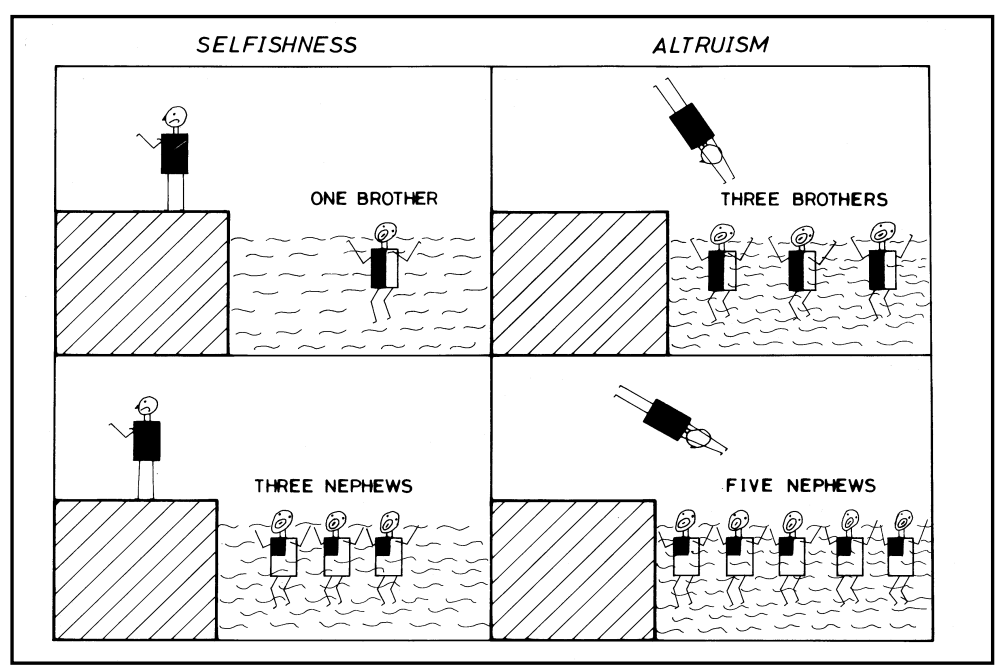

evolutionary fitness! But how do we decide if a sterile individual is just as fit or fitter than a fertile one? We have no difficulty in deciding that an individual producing two offspring is fitter than another producing only one offspring. But how do we compare the fitnesses of individuals producing one offspring and those devoting their lives to taking care of, say, one brother or three cousins or five nephews?

This is where we can go back to $\mathrm{H}$ al dane's logic. On the average, we share one half of our genes with our offspring and siblings, one fourth with our grandchildren, nieces and nephews, one eighth with our cousins, and so on (F igure 4). As far as evolution is concerned, caring for one child is equival ent to caring for one sibling, or 2 grandchildren or 2 nephews, or 4 cousins, and so on. Genetically speaking we can express any class of relatives as offspring equivalents and then compare the fitnesses of individuals with different propensities for rearing offspring or aiding relatives. $\mathrm{H}$ amilton went a step further and converted everything into genome equival ents (a genome is the entire genetic material of one individual). This is easily done by multiplying the number of offspring and siblings by 0.5 , the number of grandchildren and nieces and nephews by 0.25 , the number of cousins by 0.125 , and so on. The contribution of different classes of relatives to fitness can then be added up to yield the
Figure 3. Cartoon illustrating the theme of $\mathrm{J} B \mathrm{~S}$ Haldane's story. The shaded portions of the drowning individuals indicate the proportion of their genes which are also present in the altruist standing on the bank. Notice that the altruist is willing to risk his life when the numbers of his genes expected to be rescued is greater than the number in his body likely to be lost. (Original Drawing: Sudha Premnath)

Figure 4. Genetic relatedness under diploidy, as in humans and most animals. Notice that the relatedness (r) between two full sisters is 0.50 .

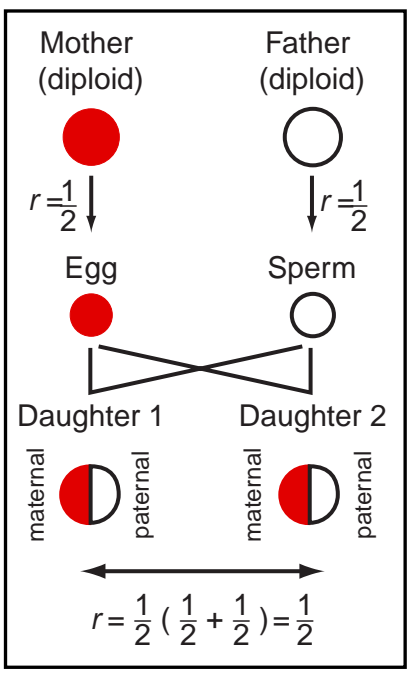


3 In the example of Haldane's story discussed here, we are assuming that Haldane was certain to die if he attempted to rescue his brothers etc., and that the drowning relatives were certain to be rescued. Of course the probabilities of these events can be less than 1.0 but then the costs and benefits of Haldane's behaviour can be easily corrected for any given set of probabilities. inclusive fitness. Now we can appreciate the hidden meaning behind $\mathrm{H}$ aldane's reluctance to risk his life to save only one or two brothers and his readiness to risk his life to save three or more brothers. B eing related to himself by 1.0 , he would need to save three or more brothers ( $0.5 \times 3$ or more) to make up for the loss of his entire genome.

\section{H amilton's Rule}

The logic I have described above has come to be known as $\mathrm{H}$ amilton's rule. Stated in more technical terms, Hamilton's rule states that an altruistic trait can evolve if the number of individuals gained, multiplied by the altruist's genetic relatedness to those gained, is greater than the number of individuals lost, multiplied by the altruist's relatedness to those lost. If $\mathrm{H}$ aldane had rescued three brothers and lost his life in the process, the number of individuals gained, multiplied by his relatedness to them $(3 \times 0.5=1.5)$ would have been greater than the number of individuals lost, $1.0(1 \times 1.0=1.0)$. Thus the al truistic trait of risking one's life to save someonein danger can evolve by natural selection, if the net ben efit is greater than the net cost (B ox 1). N otice that we can only say that the altruistic trait can evolve; we cannot assert that it will evolve. The trait can only evolve if other conditions such as having a genetic basis for the behaviour are met. It may seem unlikely that $\mathrm{H}$ aldane's behaviour of jumping into the river to save his drowning broth-

\section{Box 1. Hamilton's Rule.}

$$
b / c>1 / r
$$

$b=$ benefit to recipient, $c=$ cost to donor, $r=$ genetic relatedness between donor and recipient or

$$
n_{i} r_{i}>n_{o} r_{o}
$$

$n_{i}=$ no. of relatives reared, $r_{i}=$ relatedness to relatives, $n_{o}=$ no. of offspring reared, $r_{o}=$ relatedness to offspring.

Hamilton's rule defines the condition for the evolution of altruism. The upper form is useful to predict when an individual will be selected to sacrifice its life to help others. The lower form is useful to predict when a sterile individual who rears relatives will be selected over a fertile individual who rears offspring. 
ers has a genetic basis. H owever, $\mathrm{H}$ amilton's rule can be tested with bees and birds where there appears to be a much stronger genetic basis for behavi oural traits. We haveal ready considered the example of altruism in honey bees.

L et us now consider an examplefrom thebirds. Praveen $\mathrm{K}$ aranth and S Sridhar studied the breeding behaviour of the small green bee-eater in and around Bangal ore (F igure 5). They found that in about $40 \%$ of the birds' nest there was a hel per in addition to the breeding pair. The helpers must truly help because nests with helpers produced more fledglings per nest than nests without helpers, and these fledglings grew more rapidly and had fewer problems with predation than fledglings without helpers. $K$ aranth and Sridhar did not know the genetic relationships between the helpers and the breeding pair. But we know from other species of birds with the hel ping habit that older offspring often help their parents rear a second brood. Thus the helper is behaving al truistical ly by staying back and hel ping its parents to produce more chicks, instead of going off to breed on its own. If .. ... 'ze-eater helps its parent produce an additional hicks, its inclusive fitness as a helper is the viduals gained, multiplied by its relatedness to 1.5. If the hel per had instead gone off to breed d produced two offspring, its inclusive fitness en the number of individuals so gained, multiplied by its rel atedness to them: $2 \times 0.5=1.0$. Thus its inclusive fitness as a hel per (1.5) would be greater than its inclusivefitness as a breeder (1.0) and hence $\mathrm{H}$ amilton's rule is satisfied and the altruistic trait can evolve.

The perceptive reader would have noticed that $\mathrm{H}$ amilton's rule does not merely providea theory for theevolution of altruism. It also, simultaneously and automatically, provides a theory for the evolution of selfishness. If $\mathrm{H}$ aldane had risked his life to save just one brother, his inclusive fitness $(1 \times 0.5=0.5)$ would have been less than it might have been if he had looked the other way $(1 \times 1.0=1.0)$. If a bee-eater (that can produce two offspring if it goes away to breed) foregoes an opportunity to breed and
Figure 5. The small green bee-eater (Merops orientalis). (Photo: S Sridhar).
Hamilton's rule states that an altruistic trait can evolve if the number of individuals gained, multiplied by the altruist's genetic relatedness to those gained, is greater than the number of individuals lost, multiplied by the altruist's relatedness to those lost. 
The helpers must truly help because nests with helpers

produced more fledglings per nest than nests without helpers, and these

fledglings grew more rapidly and had fewer problems with predation than fledglings without helpers.

Figure 6. The white-fronted bee-eater (Merops bullockoides). (Photo: Natalie J Demong). becomes a helper but can only increase the number of fledged chicks in its parents' nest by 1 , it will similarly suffer a net loss in inclusive fitness. Under these conditions, selfishness is expected to evolve rather than altruism. I mentioned above that it was necessary to understand the mechanism of evolution of altruism before we could even recognise the existence of many subtle conflicts. It is because of the ability of $\mathrm{H}$ amilton's rule to explain the evolution of altruism as well as selfishness that we can now take a fresh look at conflict.

\section{Who Should Breed - Father or Son?}

L et us now see a most bizarre kind of conflict between the apparently altruistic helpers and the receivers of that help, among bee eaters. I mentioned above that $\mathrm{K}$ aranth and Sridhar did not know the genetic relationships between the helpers and the breeding pair in the small green bee eaters in Bangalore. But Emlen and Wrege had this information for their white-fronted bee eaters that they have been studying for several years in the lake $\mathrm{N}$ akuru $\mathrm{N}$ ational $\mathrm{Park}$ in $\mathrm{K}$ enya ( $\mathrm{F}$ igure 6 ). The whitefronted bee eater lives in extended family units, or clans. In each breeding season, numerous clans aggregate to form large colonies of about 200 birds each. A bout 50 percent of all nests have at least one nonbreeding helper that participates in excavating and defending the nest, incubating the eggs, and feeding the nestlings and fledglings. Every year, Emlen and Wrege painstakingly sexed and individually marked the birds for identification, and al so recorded for every nest the number of hel pers, the identity of the breeders and that of the helpers, the clutch size, the hatching success, and the fledgling success. Through such lengthy observation of the birds and their behaviour, Emlen and W rege were able to determine the genetic relationship between the helpers and the helped. With the resulting data they were able to test several different hypotheses that had been proposed to explain how helpers might benefit from helping. They found clear evidence in favour of the hypothesis that helpers act nepotistically, i.e., helpers help only when close relatives are available to receive the help and the helpers are thus able to 
enhance their inclusive fitness by hel ping.

A midst such acts of altruistic help, Emlen and W rege saw the bee eaters engage in a bizarrekind of conflict. Someindividuals, particularly adult males, harassed other members of their clan, particularly their sons, and prevented them from starting their own families. H arassment included persistently chasing potential breeders away from their territories, interfering with their courtship by preventing them from feeding their consorts, and physically preventing potential breeders from entering their nests by blocking the nest entrances. A frequent consequence of such behaviour was that the harassed individual abandoned its attempts to breed and returned to the harassers's nest to act as a helper. Why did adult males harass potential breeders in this fashion? Why did they seem to particularly choose their sons as targets of harassment? Why did the sons accede to such harassment and not resist it morefirmly? Why is it that the adult males had the greatest success in recruiting helpers through harassment when they targeted their sons? A mazing as it may seem, all these apparent paradoxes are understandable with the help of $\mathrm{H}$ amilton's rule (F igure 7). Since E mlen and W rege had all their bee eaters marked and the fate of each nest recorded, they could computethe costs and benefits of harassing as well of acceding to harassment. First let us look at the problem from the point of

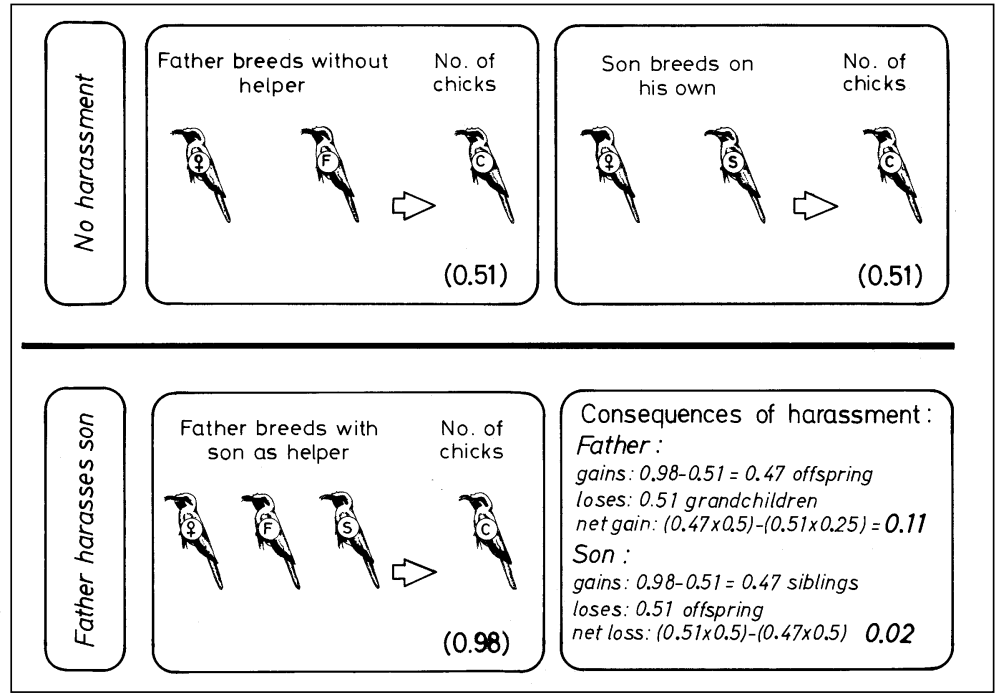

Helpers act nepotistically, i.e., helpers help only when close relatives are available to receive the help and the helpers are thus able to enhance their inclusive fitness by helping.
Figure 7. Breeding options in the white-fronted beeeater. (Based on Emlen and Wrege 1992; drawing by Sanjeeva Nayaka). 


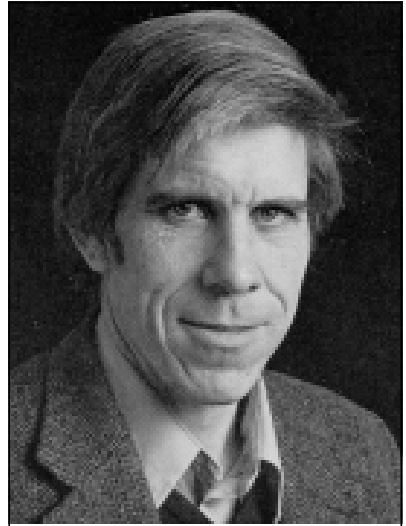

W D Hamilton

(1936-2000)

After this article was in press, I received the very sad news that Hamilton died on 7th March 2000 from serious complications arising out of a bout of malaria that he got while doing field work in the Republic of Congo in Africa. As readers will see from this article, Hamilton has laid the foundations of the modern study of animal behavior, ecology and evolution. Hamilton will be missed by everyone in this field and for those of us who knew him as one of the brightest and kindest of friends, our sorrow is difficult to describe in words. But as Bernie Crespie, Hamilton's former student says, "This is how [he] would have preferred to go, fighting malarial parasites after an expedition to the Congo to find the source of AIDS". A forthcoming issue of Resonance will feature several facets of Hamilton's life and work. view of the fathers. What are the costs and ben efits of harassing their sons? If harassment is successful, the sons will come back to the nest as helpers and increase the number of offspring that the adult males can produce. That is a ben efit. But then the sons will not breed on their own and hencetheharasser will lose some grandchildren. On the average, a nest without hel pers - with the only adults being the breeding pair - produced 0.51 offspring, while a nest with one additional hel per produced 0.98 offspring. $F$ athers who harass their sons and bring them back would gain $0.98-0.51=0.47$ offspring and lose 0.51 grandchildren. Since 0.47 offspring are far more valuable then 0.51 grandchildren (remember the father is related to his offspring by 0.5 and to his grandchildren by 0.25 ), natural selection should favour fathers who harass their sons.

But why does the son not resist? L et us now do the calculation from his point of view. A son who came back and helped his father would contribute to the production of 0.47 additional siblings and lose about the same number, 0.51 , of offspring (that he might have produced on his own). Since he is equally related to his siblings and to his offspring, it does not matter too much to the son whether he helps or breeds. T hus natural sel ection on the son will not be very strong. The fathers will be selected to keep trying to get back their sons while sons will not be selected to resist too strongly. The origin of the conflict between sons and fathers has to do with the ecological condition that almost doubles the number of chicks fledged due to the addition of a hel per. And its resolution in favour of the father rather than the son has to do with the fact that the father is twice as related to the chicks he gains (offspring) as compared to those he loses (grandchildren) while the son is equally related to the chicks he gains (siblings) as compared to those he loses (offspring).

\section{Whom to be $\mathrm{N}$ ice to - Brothers or Nephews?}

We have seen above that we share one half of our genes with our brothers and sisters. T here is no reason why brothers should be different from sisters in this matter. But that is not the case with 
honey bee workers who often care for their brothers and sisters. In all insects that belong to theorder $\mathrm{H}$ ymenoptera, such as ants, bees and wasps, the relatedness of female individuals to their brothers and sisters is not al ways the same. This asymmetry is brought about by a phenomenon called haplodiploidy or male haploidy. H ymenopteran mothers can lay both fertilized as well as unfertilized eggs. The fertilized eggs develop into diploid adult females (daughters) while the unfertilized eggs develop into haploid adult males (sons). (An irresistible aside is that $\mathrm{H}$ ymenopteran males therefore have neither fathers nor sons think about it!) Because adult males are haploid they transmit a complete copy of their genome to each sperm, rather than a randomly chosen 50 percent, as all diploid organisms do. This makes the sperms clones of each other and consequently two full sisters with the same mother and father share $75 \%$ of their genes rather than the usual $50 \%$ (F igure 8). In contrast a female bee shares only $25 \%$ of her genes with her haploid brother rather than the usual $50 \%$. H owever, since a $\mathrm{H}$ ymenopteran female is diploid she is related to her sons and daughters, each by $50 \%$, as in all diploid organisms.

Since the worker bee cannot mate she cannot produce any daughters. As far as female larvae are concerned they only have their sisters (the queen's female offspring) to take care of - there is no conflict here. As far as male larvae are concerned the situation is quite complicated - in principle a worker has three options - sons (her own haploid offspring, $r=0.5$ ), nephews (haploid offspring of other workers, $r=0.75 / 2=0.375$ ) and brothers (haploid offspring of the queen, $r=0.25$ ) (F igure 9). However, only a few workers are capable of developing their ovaries and laying a small number of haploid eggs in the presence of the queen. In practice therefore, an average worker usually has a choice between caring for her nephews and her brothers. Their choice is obvious - they should prefer to carefor their nephews to whom they are related by 0.375 rather than their brothers to whom they are related by 0.25 . F rancis $R$ atni eks has pointed out an important implication of this - workers

\section{Suggested R eading}

[1] R Dawkins, The Selfish $\mathrm{G}$ ene, $2^{\text {nd }}$ ed. Oxford U niversity Press, Oxford, 1989.

[2] R G adagkar, Survival Strategies - Cooperation and Conflict in Animal Societies, H arvard University Press, $C$ ambridge, $M$ assachusetts, USA and Universities Press, $H$ yderabad, India, 1997. 
Figure 9. Different classes of relatives and their relatedness levels available to worker honey bees under single mating and multiple mating by the queen bee (based on Ratnieks, 1988).
Figure 10. Genetic relatedness under haplodiploidy with multiple mating. Notice that the genetic relatedness between half sisters is $\mathbf{0 . 2 5}$.

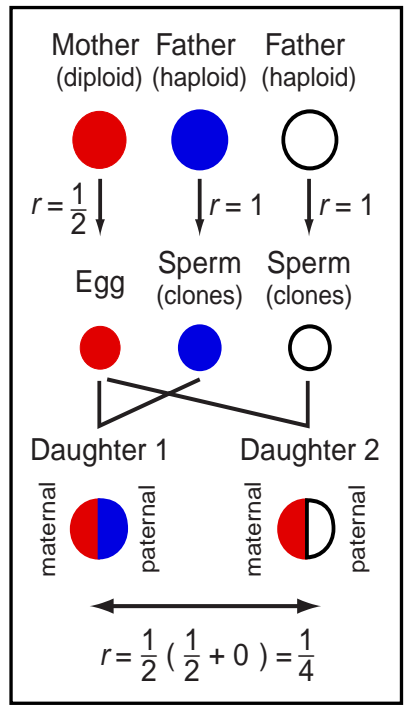

should have a common interest in revolting against the mother queen and in producing their own haploid offspring or in taking care of each other's haploid offspring. Thus little conflict is expected between the workers on the question of rearing male offspring.

But the situation changes dramatically if the queen mates with several males and uses sperm from different males in producing her daughters. The workers will now quite often be step sisters or half sisters to each other $(r=0.25)$ (F igure 10). Although each worker should continue to prefer to rear her own sons rather than her brothers, workers should now cease to prefer each other's sons over brothers. Sons of their half sisters would be related by $0.25 / 2=0.125$, a value half that of their relatedness to their brothers. Thus each worker should now prefer the queen's sons over sons of other workers. Although their first preference would still be their own sons, they would not agree on which of them should produce the male eggs. Indeed, Ratnieks has argued that workers should police each other and destroy any eggs laid by each other because they would no longer prefer nephews (sons of half sisters in this case) over brothers.

The honey bee is a good model system to test this prediction since the queens are known to mate with 10 to 20 different males. Ratnieks and Visscher used the European honey bee A pis mellifera and asked if workers actually police each other by eating each other's eggs, as predicted by theory. They found that while 


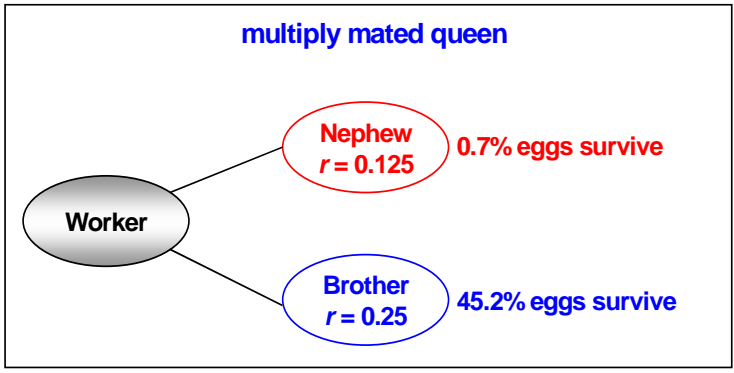

only 0.7 percent of the workers laid eggs survived after 24 hours, 45.2 percent of the queen laid haploid eggs survived after a si milar period (F igure 11). It seems rather ironic that the queen ultimately ben efits from the inability of the workers to agree on which one of them should lay the male eggs, although they all agree that it is not the queen but they who should be doing so. Is the queen's habit of mating with several males a strategy to disrupt the workers' unity and get them to fight each other? L et us conclude this example by recalling that a conflict over male production arises between queens and workers because of the differential relatedness of the workers to their brothers and their nephews. The conflict is resolved, in this case, in favour of the queens, because it is they who can decide how many males to mate with and hence it is they who decide the level of genetic relatedness among their daughters and between their daughters and nephews.

The two examples described above illustrate how, by the application of $\mathrm{H}$ amilton's rule, originally devel oped for understanding the evolution of altruism, we can discover the existence of subtle and unexpected conflicts in animal societies and begin to understand how they are resolved. I wish to close by pointing out that we have barely scratched the surface of this fascinating line of inquiry into animal societies. The future holds in store endless mysteries that are likely to be amenable to solution by combining appropriate theoretical analysis with field observati ons and laboratory experimentation. With our rich and diverse flora and fauna and the relative freedom from expensive instrumentation that such an enterprise provides, this should be an attractive field of research for biologists in India.
Figure 11. Reproductive conflict and worker policing in honey bees. When the queen bee is multiply mated, worker bees are twice as closely related to the queen's male offspring (brothers) as they are to their sister's male offspring (nephews). In accordance with this, they destroy many more haploid eggs laid by their sisters as compared to the haploid eggs laid by their queens (based on Ratnieks and Visscher, 1989).
Address for Correspondence Raghavendra Gadagkar Centre for Ecological Sciences Indian Institute of Science Bangalore 560 012, India. Email: ragh@ces.iisc.ernet.in URL'http://ces.iisc.ernet.in/hpg/ ragh 